\title{
SOFISMA DE "GLOBALIZAÇÃO" EM MERCADO MUNDIAL ENTRÓPICO
}

\author{
Luiz Sergio Modesto \\ Professor pós-doutorado com título de \\ Doutor em Comunicação e Semiótica \\ pela Pontifícia Universidade Católica de São Paulo. \\ Doutor e Mestre em Teoria do Estado, \\ Especialista em Direito Político, Administrativo e Financeiro \\ pela Universidade de São Paulo. \\ Assessor Científico ad hoc da FAPESP, \\ Fundação de Amparo à Pesquisa dọ Estado de São Paulo.
}

Resumo:

Sofisma de "globalização" em mercado mundial entrópico. O autor pretende demonstrar que os modelos teóricos cujo objeto implica a política, na Sociologia, na Teoria Política, e na Jurisprudence e Direito (Nomogogia como gênero includente respectivamente, entre outras espécies, da lex in casu [Case Law] e da lex in genere [Lex]), excluem o conhecimento científico sensu stricto ao partilharem do mesmo repertório do conhecimento comum na crença mítica da "ordem" nos mercados extraterritorial e territorial, com seus sucedâneos ficcionais de bem/mal como "globalização".

Sobre o objeto política, o autor superporá o método complexo físico-semiótico (1) da Semioselogia, includente da fenomenologia Física (Heisenberg, Bohr, Lao Tzy), da Signologia (Peirce), e do Instrumento Operacional da Progmática (Modesto), e (2) da Hominilogia (Modesto), para descrever o mercado econômico mundial, extraterritorial e territorial, na sua dominância acausal ou entrópica, em relação ao slogan da "globalização" veiculado pelo mercado político entre pluridominâncias concorrentes do mercado econômico.

$\mathrm{O}$ autor também pretende descrever essa relação entre o mercado econômico e o mercado político e demonstrar a distância entre esse slogan do mercado econômico, travestido de "argumento" pela superposição do mercado político e subposição da academia, e as implicações quantificadas entre os mercados econômicos extraterritorial e territorial, expondo a teologia que fundamenta o êxtase da "globalização"

\footnotetext{
Abstract:

Sophism of "globalization" in worldwide market entropic. The author intends to demonstrate that the theoretical models whose object implicates the politics, in the Sociology, in the Political Theory, and in the Jurisprudence and Right (Nomogogy as a gender including respectively, among other species, the lex in casu [Case Law] and the lex in genere [Lex]), exclude the sensu stricto scientific
} 
knowledge sharing the same repertoire of the common knowledge in the mythical belief of the "order" in the territorial and extraterritorial markets, with their fictional succedaneous of good / evil as "globalization"

On the politics object, the author will superpose the semiotics-physics complex method (1) of Semioselogy, including of the Physics phenomenology (Heisenberg, Bohr, Lao Tzy), of Signology (Peirce), and of the Progmatic Operational Instrument (Modesto), and (2) of Hominilogy (Modesto), to describe the extraterritorial and territorial worldwide economic market, in its chance and entropic dominance, in relation to the slogan of the "globalization", transmitted by the political market among concurrent pluridominances of the economic market. The author also intends to describe that relationship between the economic market and the political market and to demonstrate the distance between that slogan of the economic market, travestied of "argument" by the superposition of the political market and subposition of the academy, and the quantilied implications between the extraterritorial and territorial economic markets, exposing the theology that founds the ecstasy of the "globalization".

Semiosclogia; Hominilogia; superposição política; superposição Unitermos: econômica; mercado mundial entrópico; coletividade-família; coletividade-bando; coletividade-estado

Índice

I. Mando, força e crença na "ordem"

1. Sociologia, Teoria Política, Jurisprudence e Direito, e conhecimento comuın

2. Conhecimento comum: fundamento mitológico e diluição religiosa

II. Crença na "ordem” versus Mercado entrópico

3. Mercado Econômico: dominância do territorial sobre o extraterrritorial

4. "Globalização": projetos de dominância do mercado extraterritorial

\section{Mando, Força e Crença na "Ordem"}

1. Sociologia, Teoria Política, Jurisprudence e Direito, e conhecimento comum

Os modelos teóricos cujo objeto implica a política - mando ou força justificáveis (Modesto, 1994) quer pertençam à Sociologia, quer à Teoria Política, quer à Jurisprudence e Direito (Nomogogia como género includente respectivamente, entre outras espécies, da lex in casu [Case Law] e da lex in genere [Lex]), não se destacam do baixo repertório do conhecimento comum para o alto repertório do conhecimento científico. Quais os indíces de verdade nessa asserção? Primeiro: a 
ausência de ruptura cognitiva entre a baixa seletividade do conhecimento comum e a alta seletividade do conhecimento científico sensu stricto, aquele que implica hipóteses intersubjetivamente verificadas e demonstradas com sentido de universalidade em relação objetiva com a realidade, não circunscritas ao código verbal, pela persuasão e pela "asserção de autoridade" O substrato desse conhecimento comum em tais disciplinas, não cortou o cordão umbilical com a mitologia (Anônimo akkad, 1989, 1992, 1993, 1994: IV-18; Moisés, 1985-1,3-24: 31-32; Aristóteles, 1998-1252a: 48) e seus derivados terminológicos diádicos do bem/mal das teologias religiosas, como é o caso do slogan de "globalização" lançado pelo mercado político.

Assim, muitas das asserções da Sociologia, da Teoria Política, da Jurisprudence e Direito, quando se logra uma prospecção histórica de suas camadas teóricas, revela fundamentos teológicos sem os quais ruiriam os seus argumentos persuasivos, fortemente sustentados por domestiação, isto é, pelo cordão umbilical (que a insegurança impede romper) daquela cognição mitológica diádica induzida pelo tenro da mãe e o tenso do pai no estio da domus, a calma quentura do espaço doméstico onde construímos o baixo repertório do nosso conhecimento comum e visão simplificada de cosmo, para sustentar as justificativas de nossas expectativas quanto às relações nos espaços doméstico e público.

Ora, tais expectativas têm por escopo auxiliar nossos dispositivos de ação no ambiente da sobrevivência cotidiana e extracotidiana, partindo da dominância dos interpretantes emocionais, passando pela entropia ou quantidade de desordem dos interpretantes energéticos, até o resíduo dos interpretantes lógicos, ou racionais, e contudo, para efeitos de sobrevivência e cognição, invertemos essa seqüência fenomenológica, ou seta do tempo, para sobrelevar o racional, ocultando a base emocional do corpo no real, como se esse racional sistematizado em "ordem" só possível no pensamento, correspondesse linearmente ao ambiente real, reificado por essa segurança, a partir daquele diádico mitológico, como "ordem" contraposta à "desorden"- a mais comum derivação terminológica de bem/mal -, enquanto esse real implica apenas complexidade (Adams e Laughlin, 2001: 244), cujo fundamento ignorado por aquelas disciplinas é o acaso (Hawking, 2001: 161, 163).

Uma observação atenta, sincrônica ou diacrônica, dos textos teóricos de tais disciplinas, cotejados com as fontes primárias da História no jornalismo, por notícias publicadas em jornal, rádio, televisão, internet e demais meios comunicativos vai revelar o segundo índice de verdade daquela asserção: a reprodução dessa crença de que a "ordem" categoria classificatória no pensamento, espelharia uma "ordem" no real, 
que vem por aquela domestiação no espaço doméstico, é partilhada sem falsificação pela pretensão de rigor científico no conhecimento daquelas disciplinas e pelo conhecimento comum jornalístico.

Encontramos abundantes referências a tal "ordem" dando sustento "conclusivo" aos seus argumentos persuasivos nas obras Economia e sociedade, esboço de sociologia compreensiva, de Max Weber no século XX (1980: 111, 260, 689, 693 ...), na Política, de Aristóteles no século -IV (1998-1272a, 1307-b; 1253a,

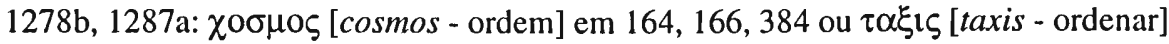
em 56, 206, 257 ...), e na Teoria Geral do Estado, de Jellinek no século XIX (1954: $320,321,361,368$...), texto protótipo das Teorias de Estado contemporâneas.

Encontramos essa mesma crença de "ordem" no real pelo noticioso jornalístico, e sempre que um fato novo reagrupa as expectativas políticas de algumas coletividades, como foi o fim da Guerra Fria entre estadunidenses e soviéticos, com a queda do muro de Berlim em 1989, que teria instaurado "uma nova ordem mundial, fundada explicitamente no espírito de modernidade e no liberalismo" (Comparato, 2002: A3), ou na recente reação árabe ao genocídio palestino, armado pela ColetividadeBando EUA e executado pela Coletividade-Bando Israel, mediante a explicitação da fraqueza destas coletividades nas retaliações ao Pentágono (184 mortos), World Trade Center (2948 mortos), e no avião abatido na Pensilvânia (40 mortos), totalizando 3191 mortos (incluindo os 19 seqüestradores árabes) em 11/09/2001, e à segunda intifada ou levante contra a ocupação da Coletividade-Bando Israel na Faixa de Gaza e Cisjordânia (2000-2002) - a primeira foi de 1987 a 1991 (Veja, 2002-1747: 49; Times, 2002-a: H2).

Essa coletividade de fundamentalismos monoteístas com Yhwh de estadunidenses e judeus e Al-llah de árabes hoje não partilha do mesmo ambiente de "ordem" Cada um desses fundamentalismos tem no outro o mal, a "desordem", encontrando nas respectivas intelligentsias serviçais na Sociologia e na Teoria Política, um defensor da sua "ordem" Nesse sentido Todd Gitlin, para quem está no fundamentalismo islâmico de árabes o conceito odioso de "ordem fixa e imutável da forma piramidal de organização" religiosa das coletividades (2001: 98).

Analisados diacrônicamente os contextos em que "ordem" implica mando e força, estes acreditados como oniefetivos no real, observaremos a dinâmica pluridominantes/periferias entre coletividades pela velocidade entre emissão e recepção do mando e da força, enquanto acato e lesão no mercado mundial, e os interesses econômicos veiculados por homicídios bélicos nesses ambientes. Para Ahmad Dallal 
(2001: 87), a milícia Talibã "restaurou ordem" no Afeganistão em 1994, depois de resistirem seus integrantes à matança de afeganes por invasores soviéticos de $1979 \mathrm{a}$ 1989. Essa "ordem" foi gerenciada pela política chimpanzé (Modesto, 2002: padrão de civilidade similar a esses hominidas, pela dominância da força), respectivamente, por Ronald Wilson Reagan (1981 a 1988), que cevou o preposto Saddam Hussein do Iraque na matança contra o Irã de 1980 a 1988, e por George Herbert Walker Bush (1989 a 1993), quando o fundamentalismo puritano estadunidense com $Y h w h$, mediante terceirização bélica liderada pelo fundamentalismo islâmico com Al-llah de Osama Bin Laden, expulsaram os soviéticos da região.

Sugestivamente, um Ersatz dessa crença na "ordem" encontra-se no título dado por um periódico para sua edição especial de início de século, "A reinvenção do Mundo" (Veja, 2001-1732). A capa do periódico ilustra o mito da "ordem" com um globo terrestre partindo-se qual ovo, e dele o resplendor do nascimento de um novo mundo. O título da seção especial, também é indutivo, "Para entender o mundo novo", uma série de artigos sobre 11/09/01, o ódio responsivo dos "excluídos" remotos e próximos do petróleo, como palestinos, árabes, afeganes ..., o fundamentalismo islâmico demonstrando a mesma competência homicida do fundamentalismo puritano estadunidense, cevador do genocídio palestino perpetrado pelo fundamentalismo judaísta, com a retaliação de 11/09/01, no World Trade Center (índice do mando excludente), no Pentágono (índice da força da política chimpanzé), e na Pensilvânia. Yhwh e Al-llah como "ordens" de força homicidas para mandos de conteúdos diversos. O signo "ordem", além daquela incidência com Dallal, volta com Franco (2001: 179) também professando fé nessa "ordem econômica internacional"

Nestes momentos, ou naqueles em que os interesses políticos de coletividades potentes, dentre as pluridominantes no mercado mundial, encontram-se ameaçados, como na probabilidade efetivada por Luiz Inácio Lula da Silva - de vitória da oposição no Brasil em 2002, e conseqüente perda de montaria de um preposto local (cargo predestinado) de nominal Coletividade-Estado, implícita ou explicitamente fala-se em "desordem" (Felinto, 2002: C2), a "ordem" não querida do diádico bem/ mal das teologias religiosas justificadas por esses absolutismos pontuais do mercado político, aliados ao capital especulativo do mercado econômico acelerando o mercadomundo.

Outro Ersatz dessa crença na "ordem" vem com o signo "globalização", repetido em 3 questões, dentre 14 dirigidas aos articulistas dessa seção especial , "Para entender o mundo novo" (2001-1732: 66-67), sem contar sua reiteração interna por 20 
vezes (2001-1732: 98, 152,164, 165, 167, 176, 177, 179, 185), chegando ao êxtase dogmático de reiteração do mantra: 25 vezes com Jacques Le Goff (2001: 158-160), num total de 45 vezes para mais. O título do texto de Goff é revelador: "Vamos construir a globalização que nos convém". Aquela "globalização" do "bem" em induzida oposição teológica à "globalização" do "mal"

2. Conhecimento comum: fundamento mitológico e diluição religiosa

A origem ocidental dessa crença na "ordem" política que fundamenta o "argumento" da "globalização" vem por domestiação do texto seminal da etnia akkad designado Enuma Elish (-XII), uma cosmogonia teogônica de autor anônimo, que tem continuidade diluidora na brutação da teofania cosmogônica da Torah (Instrução) escrita entre -IX a -V, e atribuída a Moisés. (Modesto, 1999)

No Enuma Elish, texto que também justifica o oscilo da "força" nas mesmas disciplinas aqui objeto de objeção, Sociologia, Teoria Política, Jurisprudence e Direito, como visto em Modesto, 2002, Marduk é "o ordenador e criador do cosmo" (Lara Peinado, 1994: 23, 24-25), a partir do protótipo celeste de "ordem" na residência de Marduk, um teocosmo que tem réplica na "ordem" da Babilônia terrestre. Marduk também é o fundador do monoteísmo ocidental mediante o recurso lógico de assumir num único signo as qualidades de deuses tribais diversos, assumindo seus diversificados 50 nomes para o recurso prático de efetivar uma superposição político-territorial. Um desses nomes, Asharu, implica "ordenar" "regular" "organizador". (cotejar Anônimo akkad, 1989, 1992, 1993, 1994: VI-120 a VII-144; Lara Peinado, 1994-n.74: 113; 1994: 17; 1994-n.59: 112; Astey, 1989-n.248: 95) Esse recurso ao deus-colagem em Marduk foi posteriormente recepcionado pelos hebreus ao assumirem do akkad ilu o seu dialetal ' $e l$-deus-, na teofederação 'Elohim -deuses-, includente para Yhwh, e ao menos outros 12 nomes diversos na Torah ("Instrução"). (Motyer, 1986: 157-158)

Essa crença na "ordem" por mando - implicando ausência de mudança -, conduzida pela palavra na formação de nossas expectativas domestiadas por ácades, hebreus, e gregos, e teologicamente diluída pelo judaísmo, cristianismo, islamismo, é acreditada como capaz de reproduzir-se espelhada nos destinos humanos qual "ordem" denotada no real, mediante o mando político por logos fático, o verbo executor que, se ineficiente, justifica a força para restabelecer ... a "ordem"!

De sua residência celeste, Marduk invoca seus poderes ao avô Anshar, o horizonte "céu-todo": 
“"Senhor dos deuses, fixador do destino dos Grandes deuses (...)

Convoca a Assembléia, proclama meu destino transcendente.

Na Sala das deliberações senta-os juntos alegremente,

Faze que minha palavra, no lugar da tua, destine destinos:

Que nada tenha mudança, daquilo que eu determinar,

Que minha ordem proferida seja irreversível, irrevogável"

(Anônimo akkad, 1989, 1992, 1993, 1994: II-154/161)

A prova teofânica para a entronização de Marduk está no seu mando político por logos fático que se reproduz no real como "ordem":

"Prepararam para ele [Marduk] o estrado real.

Fitando seus pais, sentou-se ele para a monarquia.

'Só tu és mais importante entre os Grandes deuses!

Teu destino é sem rival, teu mando qual de Anu! (...)

Doravante sejam tuas ordens irrevogáveis,

Exaltar ou aviltur dependerão da tua mão.

Quanto tua boca declarar será fato, teu mando infalível,

Nenhum deus transporá teus limites! (...)

A ti, Marduk, certamente nosso vingador,

Conferimos realeza sobre a totalidade do cosmo!

Quando sentado em Assembléia, tua palavra será sumo,

Tuas armas infaliveis despedaçarão teus inimigos. (...)'

Colocada entre eles uma Imagem da Constelação única,

Endereçam essas palavras a Marduk, seu primogênito:

'Senhor, se teu destino é o primeiro entre os deuses,

Ordena realidade à criação e à destruição.

Abre tua boca, tal Imagem [da Conștelação única] desaparecerá,

Fecha tua boca, tal Imagem aparecerá íntegra!'

Então, seguindo sua ordem [de Marduk], a Imagem desapareceu,

Outra ordem, a Imagem apareceu íntegra.

Quando os deuses, seus pais, viram o efeito da sua boca,

Saudaram alegremente:

'Só Marduk é rei!' A ele entregaram o cetro, o trono, a veste"

(Anônimo akkad, 1989, 1992, 1993, 1994: IV-1/4, 7/29). 
A imagem da Constelação única era o modelo de "ordem" no mando para o acato da real Babilônia terrestre, também única, c o logos fático repete-se diluído na recepção mítica do Enuma Elish, que antecipa o monoteísmo da Torah hebraica. Neste texto repete-se o verbo executor que o real espelharia como "ordem": 'Elohim manda "'Haja luz' e houve luz." 'Elohim "viu que a luz era boa, e (...) separou a luz das trevas (...) chamou à luz 'dia' e às trevas 'noite' Houve una tarde e uma manhã: primeiro dia" (Moisés, 1985-1,3-5: 31).

O modelo das idéias de Platão, exposto no Timeu, ou da natureza, também é caudatário terminológico daquele fundamento akkad da "ordem" na nomogogia ocidental. “(...) [T]udo o que nasce, nasce necessariamente por ação de uma causa (...). Assim, pois, todas as vezes que o demiurgo, com seus olhos sem cessar postos no que é idêntico a si, se serve de um modelo de tal classe, todas as vezes que ele se esforça por realizar em sua obra a forma e as propriedades daquele, tudo o que desta maneira produz é necessariamente belo e bom (...) [;] se isto é assim, resulta também absolutamente necessário que este mundo seja a imagem do outro mundo [o modelo]" (Platão, 1990-28c: 1133-1134).

II. Crença na "ordem" versus mercado entrópico

3. Mercado econômico: dominância do territorial sobre o extraterrritorial

A crença de "ordem" no mercado-mundo pode ser objetada a partir da observação de cada ambiente territorial e da aleatória dinâmica entre coletividades que o cotidiano e a história registram nesses ambientes (Modesto, 1994). Por critério de dominância macrofenomenológica relativamente à infinidade de coletividades possíveis na complexidade do real de um espaço territorial, o Ego humano pode observar três coletividades disponíveis para sintaxes diádicas de superposição política nos espaços-tempos intercorporais doméstico e público: a ColetividadeFamília, a Coletividade-Bando, a Coletividade-Estado. A superposição política ocorre por mando ou por força, com procedivel ação sígnica justificativa. A aplicação do método físico-semiótico da fenomenologia a tais Coletividades (ver fig. 1), portanto, implica irredutibilidade de suas verificações de gênero às asserções de espécie da Teoria Nomogógica e da Dogmática Nomogógica quanto aos signos Família, Bando, Estado. 


\begin{tabular}{|llllll|}
\hline \multicolumn{5}{|c|}{ CORRELAÇÕES FENOMENOLÓGICAS (SEMIOSELOGIA) } \\
PEIRCE & LAOTZY & BOHR & HEISENBERG & MODESTO \\
$1 \downarrow \downarrow$ acaso & fexibilidade yin-yang & incerteza onda-corpo possivel eutimia política: mando & Col. Família \\
$2 \downarrow$ relação & matéria & sujeito /objeto & real & mercado política: mando $V$ força & Col. Bando \\
3 & $\downarrow$ signo & conhecimento & formalismo & registro convenção política: mando & Col. Estado \\
\hline
\end{tabular}

Figura I Correlações Fenomenológicas ou seta do tempo: Peirce, Lao Tzy, Bohr, Heisenberg, Modesto

Observa-se a Coletividade-Família na intermitente superposição política, cuja liberdade no espaço-tempo intercorporal tem por dominância o acaso perpassado pela contigüidade corpo-corpo nas relações eutímicas, e pelas relą̧ões propriamente políticas de mando na temporalidade local do espaço doméstico.

Observa-se a Coletividade-Bando na intermitente superposição política, cuja liberdade no espaço-tempo intercorporal tem por dominância o contraste (por mando) ou o conflito (por força) com a Coletividade-Família no espaço doméstico e com a Coletividade-Estado no espaço público.

Observa-se a Coletividade-Estado na intermitente superposição política, cuja liberdade no espaço-tempo intercorporal tem por dominância a nomogogia convencional - contemporânea ou extemporânea, local ou geral - perpassada pelas relações entre corpo e corpo por mando na temporalidade geral do espaço público.

A (c) Coletividade (ou o Coletivo) está no conjunto fenomenológico aleatório, intermitente, e não reificável de Emissores $(E c)$ ou Receptores $(R c)$ diversificados (no campo do domínio, em relação ao campo da imagem), que tem por eixo de referência qualquer liberdade corporal ou intercorporal, quer implique a mente (liberdade da mente enquanto quale emocional), quer denote ou designe a vontade (liberdade da vontade enquanto energia), ou exprima a nomogogia (liberdade da nomogogia enquanto lógica). A intermitência da superposição de uma de tais coletividades, se altamente freqüente, pode casualmente designar como dominante o Emissor coletivo em relação às coletividades Receptoras dominadas. Nesse caso, a referência à relação dominante/dominado não implica linearidade entre coletividades, mas complexidade freqüêncial de intermitências.

A crença de "ordem" no mercado-mundo, além dessa dinâmica territorial acausal e sem "ordem" entre coletividades - a história implica o registro dessa descontinuidade -, também pode ser objetada a partir da observação das relações entre singulares Coletividades-Estado e da dinâmica assimétrica entre economias e políticas pluridominantes nesse mercado-mundo, conforme índices adiante. Em que pese a pluridominância entre economias e políticas de diversas Coletividades-Estado, contudo, 
sobrevaloriza-se o dado da potencial força de uma nominal Coletividade-Estado, para acreditá-la onipotente em "ordenar" o mercado por mando.

Essa crença de "ordem" verifica-se com a afirmação de "potência hegemônica" para a nominal Coletividade-Estado EUA (Hadley, 2001: 56), quando se ignora que essa coletividade, dentre outras 206 Coletividades-Estado no mercadomundo:

(1) partilha da pluridominância econômica com Canadá, Europa Ocidental e Japão, no total de 18 Colctividades-Estado (Batista Júnior, 1988: 181, 146-149);

(2) partilha da pluridoninância política de armas biológicas com China, Coréia do Norte, Coréia do Sul, Egito, Irã, Israel, Rússia, Síria, Taiwan, Vietnã, no total de 11 Coletividades-Estado (Falkenrath, Newman, Thayer, 2001: 92);

(3) partilha da pluridominância política de armas químicas com China, Coréia do Norte, Cuba, Egito, Iêmen, Índia, Irã, Israel, Iugoslávia, Líbia, Mianmar, Paquistão, Rússia, Síria e Taiwan, no total de 16 Coletividades-Estado (Falkenrath, Newman, Thayer, 2001: 92;

(4) partilha da pluridominância política de armas nucleares com China, Coréia do Norte, França, Índia, Israel, Paquistão, Reino Unido e Rússia, no total de 9 Coletividades-Estado (Security, 2002).

O que se nota nessas partilhas de pluridominâncias entre ColetividadesEstado, além da inexistência de uma "potência hegemônica", é a simetria entre estruturas econômicas e superestruturas políticas de poucas Coletividades-Estado, e a dominante assimetria entre tais estrutura e superestrutura comum às demais Coletividades-Estado, fatos irrelevantes: (1) quando dominâncias diversas podem se aliançar ao acaso; (2) quando se trata da potência homicida de cada uma de tais coletividades que, ao efetivarse, torna-se irreversível; (3) quando se trata da efetividade do acaso, que desguarnece pelas bordas qualquer potência, ou (4) desequilibra de súbito qualquer "Golias"

Recortando dessa complexidade econômico-política o mercado econômico, temos com o pesquisador Paulo Nogueira Batista Júnior uma descrição, por método quantitativo, de como se verifica hoje a relação da tecnologia com a dinâmica entre o mercado interno e o mercado internacional. Por ela podemos observar o alcance das conexões mnemônicas e dinâmicas do mando e das trocas no mercado mundial, coletividades territoriais oscilando, entre o mercado territorial e o mercado extraterritorial, ofertas para satisfazer carências entrópicas. 
"A ninguém escapa a extraordinária velocidade do progresso técnico em áreas como informática, telecomunicações e finanças. Essas inovações tecnológicas, associadas à diminuição dos custos de transportes, à desregulamentação de diversos mercados e à remoção de controles e barreiras, têm facilitado a crescente integração comercial e financeira dos mercados nacionais e a internacionalização dos próprios processos de produção em muitos setores. Nas últimas décadas, o comércio internacional vem crescendo quase sempre mais do que a produção mundial. Os investimentos diretos, mais do que o comércio. Ainda maior tem sido a expansão dos fluxos financeiros, muitas vezes de caráter volátil. Nos mercados de câmbio, o giro diário já supera o estoque de liquidez internacional à disposição dos bancos centrais dos paises desenvolvidos", a pluridominância das Coletividades-Estado EUA, Canadá, Europa Ocidental e Japão. (1998: 126)

Tal disponibilidade de conexões mnemônicas e dinâmicas possibilita que a superposição econômica na relação carência / oferta e a superposição política dos mandos dessas Coletividades-Estado transbordem de seus espaços territorias para o espaço extraterritorial do mercado mundial. Nesse sentido, o mercado econômico está no espaço-tempo territorial ou extraterritorial onde se expõe a relação carência/ oferta de troca, venda e compra de valores - bens e serviços -, com desazo de razão, justificativa e fronteiras. Essa relação carência/oferta no mercado é dominada por freqüências e não por nomogogia.

Contudo, os "dados sobre a distribuição geográfica dos fluxos de comércio internacional e dos movimentos de capital" implicam uma "forte concentração das atividades internacionais nos países desenvolvidos, que respondem por dois terços [convertidos em 3/5 para os efeitos comparativos adiante] ou mais dos fluxos de comércio e de capital" "EUA, Canadá, Japão e Europa Ocidental" respondem "com 61,1 \% das exportações e 67,1\% das importações em 1980. (...) No que se refere ao comércio de serviços, a participação desses países ê" de 75,2\% (Batista Júnior, 1988: 181, 146-149). Essas freqüências de superposição econômica e superposição política no espaço extraterritorial do mercado mundial em $3 / 5$, têm dominâncias regionais concorrentes em Nova York, Ottawa, Tóquio, Berlim, a pluridominância da qual se fala.

Nesse mercado-mundo, o transbordamento econômico e político do espaço territorial para o espaço extrateritorial, contudo, não é um objeto dominante, como sugerido pelo signo "globalização" implicando "totalização" e "integralização" Ao contrário. As Coletividades-Estado são mais freqüentes econômica e politicamente 
no espaço territorial, em dinâmịca com a Coletividade-Bando e a Coletividade-Família, e mais rarefeitas no espaço extraterritorial, em dinâmica concorrente com ColetividadesEstado próximas ou periféricas. Aquele quantitativo relacionado aos fluxos de comércio e de capital mais freqüentado por aproximadamente três Coletividades-Estado (centros em Nova York, Ottawa, Tóquio) e um Mercado Comum (centro em Berlim), com aproximadas 18 Coletividades-Estado até abril de 2004, pode trazer a ilusão dos domínios econômico e político da extraterritorialidade sobre a territorialidade que se fragmenta para o restante de 188 Coletividades-Estado, de um total de 206 no mercado mundial.

"Não obstante, os mercados internos continuam a preponderar, por larga margem, na absorção da produção, na gerą̧ão de empregos e no financiamento dos investimentos. Além disso, os mercados de trabalho permanecem altamente segmentados por políticas restritivas de imigração e outros obstáculos à movimentação internacional de trabalhadores" "Na economia mundial, a demanda interna dos países absorve cerca de $80 \%$ da produção. Responde (...) por $90 \%$ dos empregos. A poupança doméstica financia mais'de 95\% da formação de capital"' (Batista Júnior, 1998: 180-181; 136 ).

Dominam efetivamente, portanto, as dinâmicas coletivas territoriais de produção e consumo, trabalho e capital relativamente às dinâmicas coletivas extraterritoriais. Um índice dessa verificação está no mercado interno brasileiro: consome $89,2 \%$ de seu produto interno bruto, exporta $10,8 \%$ e importa $12,4 \%$. (Estatística, 2002-Tabela4) As superposições coletivas são territoriais e não se observa oniefetiva "globalização"

Essa dominância do mercado territorial (interno) para mais de 4/5 sobre o mercado extraterritorial (internacional), a Sociologia, a Teoria Política, a Jurisprudence e o Direito ignoram. A fragmentação competitiva entre 206 Coletividades-Estado transbordando aproximadamente em apenas $1 / 5$ de sua produção para o mercado extraterritorial, tais disciplinas igualmente ignoram. $O$ fato de aproximadamente 18 dessas Coletividades-Estado serem $\mathrm{em} 2 / 3$ as mais freqüentes nesse transbordamento residual de aproximados $1 / 5$ para o mercado econômico mundial, também é ignorado.

A "globalização" seria o mais recente Ersatz de "ordem". como modelo de organização das coletividades, cujo centro econômico e político estaria com os estadunidenses (Ramiro e Soares, 2002: 104; Alcântara e Salgado, 2002: 100). Essa idéia está ilustrada no jornalismo, mediante um globo terrestre sobre o qual, entre Nova York e Londres, ergue-se um executivo de terno: firme olhar distante, vindo de Nova York - a indução de "potência hegemônica" "ordenando" o globo qual Marduk -, ele indica à sua frente com as mãos um sentido de direção (Veja, 2002-1753: 96-97). 
Essa metáfora óptica do conhecimento comum, reiterados os seus referentes verbais do paleoliberalismo e corrupção - com mais subserviência na era FC (1990-2002), com Fernando Collor \& Fernando Cardoso, é partilhada com o Direito.

Por meio de seus legistas, o Direito justifica o mito da "ordem" promulgado no signo falso da "globalização", mediante a função hierática das asserções forenses, tais como "[a] globalização econômica (...) é apenas um juizo de fato" (Faria, 1997: 43), até a função dogmática das teleologias extemporâneas, como "[a] globalização tenha-se presente é um fato. Um fato longamente preparado pela história, que, tendo ocorrido, veio para perdurar" (Ferreira Filho, 2001: 220). Os autores legistas, como se nota, ignoram dados econômicos, e por falta de fundamento na fala, sustentam suas asserções sofismáticas no "autismo de autoridade": a palavra mágica, o texto sagrado e sem contexto quantitativo.

Além desse modelo de "ordem" papagueado por legistas, onde está então o cenário para a miragem da "globalização"? Podemos observá-lo na "vinculação mecânica entre avanço tecnológico, em áreas como informação, computação e finanças, e a suposta tendência geral à supressão das fronteiras e à desintegração dos Estados nacionais" (Batista Júnior, 1998: 126). Como observamos pelo quantitativo apresentado, trata-se o mantra efetivamente de uma simplificação vulgar e intelectualmente despreparada.

Essa vinculação mecânica entre o avanço tecnológico trazido pela internet na comunicação comercial e a afirmação de uma economia "globalizada" por exemplo, sequer encontra sustentação no número de usuários. Com uma população mundial em torno de 6,20 bilhões (Abril, 2003), o número de internautas é próximo de 591 milhões, $9,5 \%$ da população do planeta em 2002. Além desses números, um segundo índice de exclusão no mercado mundial vem com a concentração de 401 milhões de internautas nos países desenvolvidos $(6,5 \%)$, contra 190 milhões nos países em desenvolvimento $(3,0 \%)$.

São exemplares dessa disparidade entre "desenvolvidos" e "em desenvolvimento", os estadunidenses com 288,5 milhões de habitantes e 155 milhões de internautas $(53,7 \%$ da população, o primeiro em número de conexões), e o Brasil com 174,7 milhões de habitantes e 14,3 milhões de internautas $(8,1 \%$ da população, na décima primeira posição). De fato, $95 \%$ do comércio eletrônico ocorre nos países mais ricos. (Fapesp, 2003) Para um meio de comunicação que suporta trocas comerciais extremamente ágeis, além de independentes das espécies nomogógicas das Coletividades-Estado, os números beiram o inexpressivo para a reivindicação de totalização e integralização que o signo "globalização" implica. 
Conforme pesquisa de Paulo Nogueira Batista Júnior, em lugar do extático "globalização", "é preferivel utilizar termos como economia internacional' ou 'internacionalizações econômicas' mais compativeis com um quadro mundial caracterizado, fundamentalmente, pelo intercâmbio entre economias nacionais distintas" limitado a inexpressivos $20 \%$ de internacionalização da produção. (1998: 180-181)

A percepção de que o mercado econômico tem sua extensão dada pelo alcance das trocas e posteriormente pela moeda como meio de pagamento (meio elástico: do metal, passando pelo papel, ao virtual) na circulação de valores (bens e serviços) até os limites do planeta Terra, Marx no século XIX aponta existir mediante o designativo "mercado mundial" denotando a permeabilidade das fronteiras, e desde que os humanos descobriram o metal ouro (1983: 141-143, 148).

A descrição do "mercado mundial" feita por Marx, portanto, continua atual, visto que os mercados territoriais (internos) no século XXI interagem com o mercado extraterritorial (internacional) alternados por expansões e contrações dos interesses regionais (regionalismos) fragmentando o planeta, portanto em sentido contrário à implicação "totalizante" do signo "globalização"

São índices dessa fragmentação reginal do "mercado mundial" as designações Zona de Livre Comércio, União Tarifária, União Aduaneira, Mercado Comum, União Monetária ou Comunidade Econômica. Tais índices dessas ações fragmentadoras, na medida que falsificam a ação totalizante do objeto da "globalização" implicam sua qualidade domestiadora na "argumentação" doces retalhos da comunhão mágica no mundo da infância. O sentido teleológico de "ordem" nessa ação "global" revela o matiz teológico do êxtase que o signo evoca.

O caráter de universalidade da relação carência/oferta de valores trocados no mercado mundial realizou nos metais preciosos a função de padrão de preços dos valores por mediação das moedas (1983: 77-78). As moedas, segundo Ferdinando Galiani (1728-1787), "são as mais antigas [unidades de cálculo] em todos os povos" (Marx, 1983: 176 n. 7), bem por isso Marx as designa como "mercadoria onipresente" e "moeda universal" (1983: 235, 241), contribuindo para a circulação mundial de valores (1983: 144).

"Assim como a moeda, ao desenvolver-se, se transforma em moeda universal, o proprietário de mercadorias torna-se cosmopolita. (...) En si e para si, a mercadoria está acima de qualquer barreira religiosa, política, nacional e lingüística. (...) [C]om o desenvolvimento da moeda universal em oposição à moeda nacional, 
desenvolve-se o cosmopolitismo do proprietário de mercadorias sob a forma de religião da razão prática em oposição aos preconceitos hereditários religiosos, nacionais e outros, preconceitos esses que entravam a troca de substância entre os homens" (1983: 145).

Marx fundamenta essa descrição dà ancestralidade das trocas no "mercado mundial", como mais amplo que limitações de mando ou força, de fronteiras, etnias, códigos verbais, ou teologias. Esse "mercado mundial" sem modelos imperantes podemos verificar como efetivo nos registros da história e objetivamente como o ambiente público desorganizado onde os humanos encontram ofertas coletivas para as carências desorganizadas do corpo e da Coletividade-Família no espaço doméstico, da Coletividade-Estado no espaço público, e da Coletividade-Bando nos espaços desacatados, portanto relações diádicas de carência/oferta que têm na moeda a mediação satisfativa, e no território do planeta um acesso às ofertas e não um cartograma de cercas territoriais. Qualquer ação externa a essa díade mercador-consumidor implica ruído e desejo frágil de "ordem"

Como se nota, esse "mercado mundial" sem fronteiras não é típico da contemporaneidade, existe com os humanos desde que os humanos começaram a satisfazer coletivamente suas carências, contudo, implica asserção verificável e diversa daquela postulada como "fato" pelo signo falso "globalização" veiculando a idealização não efetiva de suposta dominância das trocas no mercado extraterritorial sobre as trocas no mercado territorial e doméstico. Por isso o "mercado mundial" dominantemente entrópico resiste e rompe políticas, etnias ou centros de "ordem". se vinculativos, apontando-se a percepção dessa dinâmica já no século - $\mathrm{V}$ pelos gregos, por meio da peça teatral Antígona, de Sófocles (-496 a -406). Ali, quem expressa a percepção da dominância da moeda sobre a convenção da Coletividade-Estado é Creonte, preposto autocrata da nominal Coletividade-Estado Tebas. Para Creonte, o dinheiro, por sua circulação expansiva, rompe as fronteiras territoriais das Coletividades-Estado para chegar ao espaço doméstico, "destrói os Estados; (...) caça os cidadãos en suas casas; é ele cujas lições seduzem os corações honestos, os faz beijar a infâmia. Ele os ensina todos os crimes, ele os ensina a impiedade que ousa tudo" (Sophocle, 1994: 82).

Apontando um texto do século XVII, Marx menciona o matemático e astrônomo Geminiano Montanari (1633 a 1687) com uma descrição contraposta àquela que traveste fragmentos de "mercado mundial" no signo "globalização" e como se fosse algo novo. No que concerne à possibilidade e não à sua probabilidade, nem o signo inova, notaremos. "As trocas entre os povos [la comunicazione de'popoli insieme] estão de tal modo difundidas em todo o globo terrestre [per tutto il globo terrestre], 
que hoje em dia podemos considerar o mundo inteiro [il mondo tutto] como uma grande cidade [una sola cittá] com uma feira perpétua de todas as mercadorias, onde qualquer pessoa pode, por meio do dinheiro e sem ter que sair de casa, obter tudo o que a terra, os animais e a indústria dos homens produzem em toda a parte, e usufrui-lo. Maravilhosa invenção!" (1983: 313 n. 38).

Não escapou a Montanari nem mesmo o dado, politicamente relevante, de tratar-se o fato de múltiplas relações de comunicação no planeta, independentes de dominâncias extraterritoriais ou territoriais: "[é] cosi fattamente diffusa per tutto il globo terrestre la comunicazione de'popoli insieme". Montanari certamente referia-se à superposição política de Coletividades-Estado da Europa que, desde o século XV, transbordavam econômica e politicamente de seus espaços territorias para o espaço extraterritorial do mercado mundial mediante colonizações. Aqui está um dos ignorados precedentes históricos das experiências de transbordamento do espaço territorial para o espaço extraterritorial dos mercados econômicos e dos mercados políticos. Como sugerido por Batista Júnior (1998: 129), a "globalização" seria um meio contemporâneo de dar continuidade à colonização. Sua veiculação no mundo acadêmico brasileiro ou estrangeiro indiciaria o atavismo dessa mentalidade colonial.

Há outro precedente de transbordamento parcial dos mercados econômico e político territorial para os mercados extraterritoriais. Entre 1870 e 1914 as relações econômicas e políticas no mercado mundial apoiavam-se em comunicação e transporte de longa distância, mediante cabos telegráficos submarinos internacionais, transporte por ferrovias e navios a vapor possibilitando velocidade e redução de custos operacionais. Em alguns aspectos o alcance do transbordamento dos mercados econồmico e político observado a partir de 1970 é até menor àquele entre 1870 e 1914 . (Batista Júnior, 1998: 131)

O modismo terminológico subserviente, acrítico ou - o que é pior intelectualmente desaparelhado, vincula o travestido signo "globalização" de um objeto falso (a ficção de dominância do mercado extraterritorial sobre o territorial) a um sentido de "ordem" hierárquica no mercado econômico mundial, sem notar sua entropia, e sem notar nesse sentido um mando de "ordem" fundado mais num projeto e menos na realidade, que tem sede no "mercado políitco mundial" mando sustentado pela nominal Coletividade-Estado EUA e executado diretamente pela Coletividade Bando EUA ou por terceirização bélica, nos diversos focos de matança do planeta, como se fosse um Yhwh de paletó e gravata posando de executivo, servido pela corte que o mundo acadêmico oferece. 
Vem desse mando justificado na "globalização" sua imagem rota de império. "[U]ma linha mais ou menos contínua de perseverança da globalização como futuro da história". Ao "redor de um centro, de uma cidade, sede de um organismo de intpulsão, da bolsa, funcionam 'satélites' mais ou menos afastados. A relação centroperiferia domina esse sistema espacialmente hierarquizado [geografia da "ordem" e acato]. Foram os casos sucessivamente de Antuérpia, Amsterdã, Londres e Nova York. (...) Na Antiguidade, foi a Roma mediterrânea, da Idade Média ao século XIX, a Europa, hoje em dia, os Estados Unidos" (Goff, 2001: 158).

O que tais "centros" econômicos (ou políticos?) têm a oferecer para outros protagonistas, coadjuvantes e figurantes? Um modelo político de mando gestor do mercado (mundial) e das coletividades de acato, por intervenção expressa ou oculta, e o mando da "nova ordem" sustentado na força, com uma agenda expressa de "liberalismo" e outra dissimulada de protecionismo. Esse "liberalismo" exprime o catecismo do mercado político do século XIX, que pontuava para o individualismo na liberdade autônoma do mercado econômico um État gendarme garantindo por nomogogia a segurança da propriedade, dos contratos, e do capital, para o acato do trabalho e do consumidor. Essa volta ao passado chamada "neoliberalismo" pelo fato de não acrescentar fundamento novo, pode ser designada "paleoliberalismo" (Batista Júnior, 1998: 154-154-155).

Para levantar o índice de comunicação de um mercado econômico, temos de aferir o alcance na circulação de seus valores (bens e serviços) no mercado econômico mundial, o quantum de trocas do mercado econômico territorial transborda para o mercado extraterritorial. Se tomarmos os valores produzidos pelos dois últimos reivindicados "centros" do planeta - Londres em 1913 e Nova York em 1997 -, o alcance na circulação de seus produtos no "mercado mundial" é curto, vale dizer, "a participação do comércio exterior no PIB [Produto Interno Bruto] é bastante limitada" (Batista Júnior, 1998: 137), correspondendo hoje à inexpressiva superposição econômica do mercado territorial de aproximados $20 \%$ no mercado extraterritorial, quando se tem à disposição nas áreas de informação, computação, transportes e finanças meios tecnológicos não sonhados na Londres de 1913.

Em 1913 os ingleses, cujo mercado econômico territorial era o que mais transbordava para o mercado extraterritorial, consumiam $57 \%$ de seu produto interno bruto (PIB), exportando 43\%, e cm 1997 os estadunidenses consomem $85 \%$ de scu PIB, exportando aproximadamente 15\%. "Centros" da "globalização"? "O Japão ["satélite" ou "centro" concorrente?] exibe um índice similar [ao alcance de $15 \%$ dos 
estadunidenses]. Ena União Européia [mais um "centro" concorrente?], cujos membros praticam uma economia nuito mais aberta, esses índices oscilam entre $25 \%$ e 35\%" "De tudo que se produz no mundo, $80 \%$ é consumido no próprio país onde foi feito. A poupança de cada nação financia quase a totalidade do seu próprio capital. E 90\% dos empregos são gerados pela demanda interna" (Passos, 1997: 70)

Os "satélites" desses sucessivos centros únicos, vislumbrados por Jacques Le Goff em determinados períodos históricos, vistos sem as lentes do mercado político e pelos índices do mercado econômico, quantificam a entropia pluridominante de protagonistas concorrentes sincrônicos sem um centro no mercado mundial. "Centro", como se observa, é um constructo problemático do mercado político, não um dado do mercado econômico.

Portanto, não há qualquer resguardo intelectual na "avaliação" da intelligentsia áulica quanto àquelas referências de centro único feitas pelo "mercado político" Un "centro" implica contraste e conflito concorrenciais com múltiplos "centros" contemporâneos de mando e força no "mercado econômico" das relações de carência / oferta. As figuras de pensamento do mando de "globalização" são projetadas no real do mercado econômico, e o mercado econômico teima em desfocar de um "centro" para múltiplos "centros" protagonistas no ódio de September 11, 2001.

A nominal Coletividade-Estado EUA, para ficar no prefácio da Coletividade-Bando, com o big stick da política chimpanzé (Modesto, 2002) associada a genocídios internos (índios e negros) e externos (japoneses em Hiroxima e Nagasaki, palestinos por terceirização de judeus, e mais recentemente iraquianos), esqueceu o trilema de Maquiavel amor, temor ou ódio: preferir o amor e o temor; sem o amor, assegurar o temor, entretanto, evitar o ódio. (Maquiavel, 1979: 70) Também não nota quando menos - a contemporânea pluridominância política concorrente do Japão, Alemanha, União Européia, além dos coadjuvantes e figurantes do mercado mundial. Para o modelo político "globalização" só há "o centro" um só protagonista sem coadjuvantes e figurantes. $\mathrm{O}$ absolutismo pontual.

A petitio principii da "globalização" - o "mercado mundial" acreditado como "ordem" ou modelo - deixa escapar até a observação elementar da história recente, o fato de essa "[im]potência" estadunidense ter tido a necessidade de, literalmente, "passar o chapéu" pelo mercado das nominais Coletividades-Estado aliadas para enfrentar, na Guerra do Golfo de 1991, o iraquiano Saddam Hussein e retomar o Kuwait, invadido em 1990, e, agora, novamente, dispender 26 dias após aquela retaliação islâmica de 11/09/0I contra a Coletividade-Bando EUA em Nova York e Washington, 
para costurar alianças homicidas, buscando enfrentar os suspeitos mandantes liderados pelo árabe Osama Bin Laden, da organização Al Qaida, ditos por George Walker Bush "homens das cavernas" do Afeganistão. Pois este "homem das cavernas", com sua potência tecnológica emprestada da "United States (...) position of unparalleled military strength and great economic and political influence" (America, 2002) - aeronaves, querosene $\mathrm{e}$ ódio -, permanece desde September 1I, 200I o vetor vivo (Times, 2002-b: A9) do medo dos cawboys alcoólatras de Washington, que designa "gangue criminosa da Casa Branci"

Tais alianças partilhadas por pluridominâncias políticas sujeitas ao acaso demonstram inexistir um "mercado mundial" subsumido à "ordem" bem assim, um "centro" onipotente de mando para uma periferia de acato "globalizado" Como lembrado pelo economista John Kenneth Galbraith, ex-assessor de John Fitzgerald Kennedy (1961-1963), e Lyndon Baines Johnson (1963-1969), prepostos da nominal Coletividade-Estado EUA, "[n]ós, os [norte-]americanos, inventamos o termo para dissimular nossa política de ingresso em mercados de outros países. E para tornar respeitáveis movimentos especulativos de capital, que sempre causam graves problemias" (1997: 72).

As intelligentsias colonizadas acataram o mando político do modelo da "ordem", e a epifania da "globalização" tem altar nas suas teorias. Sociologia, Teoria Política, Jurisprudence e Direito: mitologia religiosa no conhecimento comum e não ciência sensu stricto. Conquanto domine o acaso no suporte material do corpo, no seu ambiente, e na razão do mando, no mercado territorial ou no mercado extraterritorial, a lógica que fundamenta a crença na "ordem" e no seu sucedâneo "globalização" é a de Marduk:

'Só tu ["potência hegemônica"] és mais importante entre os Grandes [deuses!

Teu destino é sem rival, teu mando qual de Anu! (...)

Doravante sejam tuas ordens irrevogáveis, Exaltar ou aviltar dependerão da tua mão.

Quanto tua boca declarar [a "globalização"] seráfato, teu mando [infalivel, Nenhum deus [de Ottawa, Tóquio ou Berlim] transporá teus limites!

(...) A ti, Marduk[-EUA], certamente nosso vingador,

Conferimos realeza sobre a totalidade do cosmo!

Quando sentado em Assembléia [da ONU], tua palavra será sumo,

Tuas armas infalíveis despedaçarão teus inimigos (...)'

(Anônimo akkad, 1989, 1992, 1993, 1994: IV-1/4). 
4. "Globalização": projetos de dominância do mercado extraterritorial

As relações políticas entre as coletividades akkad, hebraica e grega era monolítica. Suas alividades econômicas primárias, secundárias c terciárias cram vivenciadas como atividades míticas fundadas na "ordem" celeste por nomogogia religiosa, e reproduzidas no real do espaço doméstico por domestiação. "A religião servil como mediadora nas relações do homem com o homem, e na relação do homem com o mundo natural' (Toynbee, 1986: 350). Hoje, ainda que tais atividades econômicas não sejam ostensivamente vivenciadas como míticas, persiste a postulação do conceito de "ordem" como próprio do real (item 2), postulação recapeada pelo signo "globalização" (item 3), e como fundamento da indistinção entre o conhecimento comum e o conhecimento que dele pretende destacar-se como se fosse científico, como vimos nos textos teóricos de Weber, Aristóteles, Jellinek, no noticioso jornalístico (item 1) e nos textos legistas (item 3 ).

No conhecimento comuri:, a Sociologia, a Teoria Política, a Jurisprudence e o Direito incluídos, a asserção do "global" implica um resíduo mitológico de crença na "ordem" como fundamento das relações econômicas, asserção religiosamente diluída no mercaúo político e abrangida pelo slogan dissimulado de "argumento" no signo "globalização". O "argumento" passa desapercebido, em parte porque aquela crença na "ordem" de Marduk é a base mítica de toda a diluição religiosa domestiadora que tem por referência a Torah hebraica - judaísmo, cristianismo, islamismo -, e em parte porque do conhecimento comum não se diferenciaram pelo repertório e crítica tais disciplinas do conhecimento acadêmico.

A síntese referencial do modelo da "ordem" na cosmologia clássica do inglês Isaac Newton (XVIII), sustentada no seu ápice com Albert Einstein no século $\mathrm{XX}$, vencido nas pesquisas contemporâneas pelo modelo do acaso (possível tao - 可 道 k'e tao; incerteza onda-corpo; possible; chance; Lao Tzy, Bohr, Heisenberg, Peirce), entretanto, permanece tendo utilidade sofismática na superposição do mercado político e na parcela acadêmica a ele subposta.

Essa observação dos fatos dominados pelo acaso fenomenológico, verificada e demonstrada em pesquisa, a partir da incerteza nas interações físicas qualificando a matéria no real, Heisenberg apresentou mediante corte fenomenológico triádico, controlado anteriormente por Peirce pelo rigor de uma diagramação do que é fenômeno até seu registro sígnico em classes (Peirce, 1978-2.254/263: 146-149), no qual se inclui tudo que vem à mente, aparelhada ou não. Essa tríade fenomenológica 
em qualquer observação, Heisenberg descreve no sentido físico designado por Hawking (1997: 182-187) de "seta do tempo": "a transição do 'possivel' [possible] até o 'real' [actual] (...) é conectada (...) com o nosso conhecimento no instante do registro [registration]" (Heisenberg, 1989: 42-43).

Com a mesma lógica física da seta do tempo, sempre pela observação atenta da ciência sensu stricto, e não pela fabulação mítica e teológica presente no conhecimento comum e nas disciplinas apontadas, Peirce assevera que "[a] fenomenologia investiga e estuda as espécies de elementos universalmente presentes no fenômeno, significando por fenômeno, tudo que está em qualquer tempo e de qualquer modo presente para a mente" (1978-1.186: 78). Aquela seqüência fenomenológica da física triádica a seta do tempo -, a semiótica de Peirce apresenta mediante ordinais: "[n]ão é surpreendente descobrir que além dos três elementos de Primeiridade [acaso], Secundidade [relação], e Terceiridade [signo], não há nada a mais para ser descoberto no fenômeno" (1978-1.347: 177).

Uma descrição fenomenológica correspondente à da Física de Werner Karls Heisenberg e Niels Bohr (1995), antecipadamente diagramada por Peirce, encontramos no precedente histórico da Cosmologia de Lao Tzy (ver fig. 1), da etnia han, com possivel tao 可 道 $k^{\prime}$ e tao -, oscilando a flexibilidade (i) yin-yang na matéria (chih) modificável (yü), "[M]atéria [chih] real igual modificada [yü] (...) inúmeras coisas agüentam yin contudo abraçam yang, infundem alento então feito harmonia (...) céu inferior enquanto difícil maneje por flexivel [i]" (Lao Tzy, Inédito$1,41,42,63)$.

Essa matéria entrópica desorganizada é o suporte das interações cognitivas, igualmente mediadas por incerteza dos signos (Modesto, 1999-6: 30), e também o suporte do corpo material dos humanos com suas relações de carência / oferta contaminando o mercado econômico territorial ou extraterritorial com sua entropia efetivando fragmentações regionais, onde o Ersatz de "ordem" só subsiste enquanto projeto no signo "globalização" vulgarizado como slogan do conhecimento comum, por sua instrumentalidade para as pluridominâncias políticas tentarem vencer a dominância do mercado territorial (interno) sobre o mercado extraterritorial.

Nesse caso, o "argumento" acadêmico, por sua pseudocientificidade, serve para instrumentalizar aqueles interesses do mercado econômico que, quantificados aproximadamente em $20 \%$, transbordam do mercado territorial para o mercado extraterritorial, alavancados pelo acesso coletivamente restrito à tecnologia na informação, finanças e transportes, para o consumo dominante dos segmentos mais 
diretamente beneficiados por esse transbordamento, elites consumidoras encasteladas nas coletividades acadêmicas e nas burocracias das Coletividades-Estado. $\mathrm{O}$ deslımbramento produzido por essa visão parcial, a desconexão entre pesquisa $\mathrm{e}$ argumento, acrescidos à miopia acadêmica para as exclusões coletivas ao mercado extraterritorial, servem como pano de fundo para o sucesso sem raiz do sofisma da "globalização"

Extremando a relação dos objetos com seus respectivos signos:

(1) o signo "mercado mundial" pelo fato quantificado de implicar verificado o transbordamento do mercado territorial em aproximadamente $20 \%$ para o mercado extraterritorial, denotando a permeabilidade das fronteiras, exprime um objeto real;

(2) o signo "globalização" pelo fato de não implicar e não denotar a dominância do mercado extraterritorial sobre o mercado territorial, verificando-se o contrário de sua asserção, e pelo fato quantificado de dominar o mercado territorial em aproximadamente $80 \%$ sobre o mercado extraterritorial, exprime um objeto ficcional.

Quando muito, a "globalização" pode implicar projetos políticos de uperposição econômica - cada potência econômica com a sua "globalização" Seu bjeto contudo seria refcrido na inversão do presente nacional sobre o internacional, para a fulura dominância do mercado extraterritorial sobre o territorial, êxtase dogmático das atuais pluridominâncias econômicas reificado no dispositivo de acesso ao extracotidiano designado "globalização" - o alter-mente (medicamento $\cong$ alimento $\cong$ "droga") da moda. No cotidiano do "mercado mundial" o que se observa é a regionalização dos mercados.

São Paulo, julho de 2003. (Atualizado pelo autor em maio de 2004) 
Referência Bibliográfica

ABRIL, Almanaque (2003). CD-ROM. Mundo. População mundial. Países mais populosos. São Paulo: Editora Abril.

ADAMS, Fred; LAUGHLIN, Greg (2001). Uma biografia do universo: do big bang à desintegração final. Traduzido por Vera Ribeiro. Revisão técnica por Alexandre Cherman, astrônomo da Fundação Planetário do Rio de Janeiro. Rio dẹ Janeiro: Jorge Zahar Editor.

ALCÂNTARA, Eurípedes; SALGADO, Eduardo (2002). A vitória dos ricos na globalização. Em Veja. P. 96-102. Edição 1753. 29/05/02. São Paulo: Editora Abril.

AMERICA, United States of [North] (2002). The National Security Strategy of the United States of [North] America. September 2002. George Walker Bush. 25/09/ 02. Washington: <http://www.whitehouse.gov/nsc/nss.pdf >.

ANÔNIMO AKKAD(1989). El poema de la creación Enuma Elish. Traducido del acadio a partir de cinco grupos de fragmentos de Nínive, del neobabilónio de Assur, de Kish, de Uruk y de Sultantepe con colación de versiones y notas por Luis Astey V. Colección de Cultura Universitaria n 46. P. 17-76. Serie Poesía. México, D. F.: Universidad Autonoma Metropolitana.

ANÔNIMO AKKAD (1992). The Creation Epic. In Ancient near eastern texts relating to the old testament. Akkadian Myths and Epics. Translated from accadian text and annotated by E. A. Speiscr. Additions to Tablets V-VII translated and annolated by A. K. Grayson. P. 60-72, 501-503. Edited by James B. Pritchard. Princeton: Princeton University Press.

ANÔNIMO AKKAD (1993). L'Enuma elish ou L'Épopée de la création. En Lorsque les dieux faisaient l'homme: mythologie mésopotamienne. Traduction du akkadiens par Jean Bottéro et Samuel Noah Kramer. Bibliothèque des histoires. P. 604-653. Paris: Éditions Gallimard.

ANÔNIMO AKKAD (1994). Enuma elish - poema babilónico de la creación. Edición y traducción del acadio dialetal por Federico Lara Peinado. Colección Paradigmas. Biblioteca de Ciencias de las Religiones. P. 45-89. Madrid: Editorial Trotta. ARISTÓTELES (1998). Política. Edição bilingue. Traduzido do grego por António Campelo Amaral e Carlos de Carvalho Gomes. Colecção: Vega Universidade / Ciências Sociais e Políticas. Lisboa: Vega.

ASTEY, Luis V. (1989). Notas. Em El poema de la creación Enuma Elish. Traducido del acadio a partir de cinco grupos de fragmentos de Nínive, del neobabilónio de Assur, de Kish, de Uruk y de Sultantepe con colación de versiones por Luis Astey V. Colección de Cultura Universitaria n 46. Serie Poesía. P. 14-16; 81-96. México, D. F.: Universidad Autonoma Metropolitana.

BARELLA, José Eduardo (2002). "Nós vamos matar você" Em Veja. Internacional. Edição 1778. P. 50-51. 20/11/02. São Paulo: Editora Abril. 
BATISTA JÚNIOR, Paulo Nogueira (1998). Mitos da "globalização" Em Estudos avançados - Universidade de São Paulo. V. 12, n 32. Janeiro/Abril de 1998. P. 125-186. São Paulo: Instituto de Estudos Avançados da Universidade de São Paulo.

BOHR, Niels (1995). Física atômica e conhecimento humano ensaios 1932 1957. Traduzido por Vera Ribeiro. Revisão técnica pelo físico Ildeu de Castro Moreira, do Instituto de Física da UFRJ. Rio de Janciro: Contraponto.

COMPARATO, Fábio Konder (2002). Religião e política. Em Folha de São Paulo. P. A3. 09/04/02. São Paulo: Empresa Folha da Manhã.

DALLAL, Ahmad (2001). Só democracia e riqueza derrotam os radicais do islã. Em Veja. Edição 1732. P. 84-87. 26/12/01. São Paulo: Editora Abril.

ESTATÍSTICA, Instituto Brasileiro de Geografia e IBGE (2002-Tabela4). Economia. Contas Nacionais. Contas-nacionais-do-Brasil. 09/06/02. <http:// www.ibge.gov.br/estatistica/economia/contaspubli-cas/tabe la4.shtm>.

FALKENRATH, Richard; NEWMAN, Robert; THAYER, Bradley (2001). America's Achilles' hell nuclear, biological and chemical terrorism and cover attack. Em Veja. Edição 1720. Guerra invisível: países que têm armas químicas ou biológicas. P. 92. São Paulo: Editora Abril.

FAPESP, Agência (2003). Mais de 590 milhões de internautas. Notícias. ECommerce and Development Report 2003. Relatório da Conferência das Naç̃̃es Unidas para o Comércio e o Desenvolvimento (UNCTAD). 29/11/03. <http:// www.agencia.fapesp.br/boletim_dentro.php?data[id_materia_boletim] $=964>$.

FARIA, José Eduardo Campos de Oliveira (1997). Direitos humanos e globalização econômica: notas para uma discussão. Em Estudos avançados Universidade de São Paulo. V. 11, n 30. Maio/Agosto de 1997. P. 43-53. São Paulo: Instituto de Estudos Avançados da Universidade de São Paulo.

FELINTO, Marilene (2002). O candidato dos Estados Unidos. Em Folha de São Paulo. P. C2. 09/04/02. São Paulo: Empresa Follha da Manhã.

FERREIRA FILHO, Manoel Gonçalves (2001). A democracia no limiar do século XXI. São Paulo: Editora Saraiva.

FRANCO, Gustavo (2001). O desafio à globalização vai além da economia. Em Veja. Edição 1732. P. 176-179. 26/12/01. São Paulo: Editora Abril.

GALBRAITH, John Kenneth (1997). Entrevista ao "Il Corrieri della Sera". Mitos da globalização 1: nem tudo é verdade. Por Maria Helena Passos. Em República. № 14. Dezembro de 1997. P. 70-72. São Paulo: D’Avila Comunicações.

GITLIN, Todd (2001). O antiamericanismo é o radicalismo dos tolos. Em Veja. Edição 1732. P. 96-99. 26/12/01. São Paulo: Editora Abril.

GOFF, Jacques Le (2001). Vamos construir a globalização que nos convém. Em Veja. Edição 1732. P. 158-160. 26/12/01. São Paulo: Editora Abril. 
HADLEY, Mark (2001). Entrevista. Em Veja. O vírus anti-USA. P. 54-63. Edição 1720. P. 56. 03/10/01. São Paulo: Editora Abril.

HAWKING, Stephen (1997). Breve história do tempo ilustrada. Editor Geral Marcelo Samuel Berman, Departamento de Física do ITA. Traduzido por Clara Allain. Revisão Científica Rubens de Melo Marinho Júnior. Curitiba: Editora Albert Einstein.

HAWKING, Stephen (2001). O universo numa casca de noz. Traduzido por Ivo Korytowski. Revisão técnica por Augusto Damineli, USP. São Paulo: Editora Mandarim.

HEISENBERG, Werner (1989). Physics and Philosophy. Introduction by Paul Davies. London: Penguin.

JELLINEK, Georg (1954). Teoría General del Estado. Traducido de la segunda edicion alemana y prologo por Fernando de los Rios. Editora Albatros: Buenos Aires.

LAO TZY (inédito). Tao. Reversão chinês-português por Luiz Sergio Modesto. Fonte nos manuscritos da Fa Chia (Escola Modelar) de Ma Wang Tui (-II), da Tao Chia (Escola Tao "Cósmico") de Wang Pi (+III), c da Tao Chiao (Escola "Mística") de Shang Hai Pan (+XX; Xilogravura de Shang Hai; explicação e comentário por Han Shan). São Paulo: Sibila Edicção.

LARA PEINADO, Federico (1994). Introducción y Notas. Em Enuma elish poema babilónico de la creación. Edición y traducción del acadio dialetal por Federico Lara Peinado. Colección Paradigmas. Biblioteca de Ciencias de las Religiones. P. 935; 91-113. Madrid: Editorial Trotta.

MAQUIAVEL, Nicolau (1979). O príncipe. Em Maquiavel, os pensadores. Traduzido por Lívio Xavier. São Paulo: Editora Abril.

MARX, Karl (1983). Contribuição à crítica da economia política. Traduzido por Maria Helena Barreiro Alves. São Paulo: Martins Fontes.

MODESTO, Luiz Sergio (1994). As Drogas do Estado. Tese multidisciplinar fundamentada no paradigma metadisciplinar da Semioselogia apresentada perante a Faculdade de Direito da Universidade de São Paulo USP -, e defendida em 30/06/95, para obtenção do título de Doutor em Direito do Estado (Política). São Paulo: Sibila Edicção.

MODESTO, Luiz Sergio (1999). Arquétrio Fratura Colateral da Cultura. Tese multidisciplinar fundamentada no paradigma metadisciplinar da Semioselogia apresentada perante o Programa de Estudos Pós-Graduados em Comunicação e Semiótica da Pontifícia Universidade Católica de São Paulo - PUC-SP -, e defendida em 21/09/99, para obtenção do título de Doutor em Comunicação e Semiótica, em Curso de Pós-doutorado. São Paulo: Sibila Ediç̧ão.

MODESTO, Luiz Sergio (2002). Política: (re)composição do objeto. Em Revista da Faculdade de Direito - Universidade de São Paulo. P. 527-574. V. 97, 2002, janeiro/ dezembro. São Paulo: Universidade de São Paulo, Faculdade de Direito, Serviço Técnico de Imprensa. 
MOISÉS (1985). Gênesis [B'reshit]. Em A Bíblia de Jerusalém. Traduzido por Domingos Zamagna, diretamente dos originais da Bíblia Hebraica de Stuttgart, com notas da École Biblique de Jérusalem. P. 31-105. São Paulo: Edições Paulinas.

MOTYER, J. A. (1986). Os nomes de deus. Em O mundo da bíblia. Traduzido por José Raimundo Vidigal. P. 157-158. São Paulo: Edições Paulinas.

PASSOS, Maria Helena (1997). Mitos da globalização 1: nem tudo é verdade. Em República. № 14. Dezembro de 1997. P. 70-72. São Paulo: D’Avila Comunicações.

PEIRCE, Charles Sanders (1978-1). Principles of philosophy. In Collected papers of Charles Sanders Peirce. V. I. Cambridge: The Belknap Press of Harvard University Press.

PEIRCE, Charles Sanders (1978-2). Elements of logic. In Collected papers of Charles Sanders Peirce. V. II. Cambridge: The Belknap Press of Harvard University Press.

PLATÃo (1990). Timeo, o De la naturaleza. Em Platón obras completas. P. 1126-1179. Traduccion del griego, preambulo y notas Francisco de P. Samaranch. Madrid: Aguilar.

RAMIRO, Denise; SOARES, Lucila (2002). A luta para entrar na festa. Em Veja. P. 104-107. Edição 1753. 29/05/02. São Paulo: Editora Abril.

SECURITY, Institute for Science and International ISIS (2002). Nuclear weapons programs worlwide: an historical overview. 21/11/02. <http://www.isisonline.org $>$.

SOPHOCLE (1994). Antigone. En Les trachiniennes. Antigone. Traduction du grecque par Paul Mazon. P. 71-122. Édition bilingue. Paris: Les Belles Lettres.

TIMES, The New York (2002-a). Os números. Em $O$ Estado de São Paulo. Panorama. 11/09/02. P. H2. São Paulo: O Estado de São Paulo.

TIMES, The New York (2002-b). Voz na fita é de Bin Laden, concluem EUA. Em Folha de São Paulo. Mundo. 19/1 1/02. P.A9. São Paulo: Empresa Folha da Manhã.

TOYNBEE, Arnold Joseph (1986). Um estudo da história. Traduzido por Isa Silveira Leal e Miroel Silveira. Brasília: Editora Universidade de Brasília; São Paulo: Editora Martins Fontes.

VEJA (2001-1732). Pará entender o mundo novo. Em Veja. Edição 1732. P. $65-$ 186. 26/12/01. São Paulo: Editora Abril.

VEJA (2002-1747). Só a dor é a mesma. Em Veja. Edição 1747. P. 46-49. $17 /$ 04/02. São Paulo: Editora Abril.

VEJA (2002-1753). A vitória dos ricos na globalização. Em Veja. Especial. Edição 1753. P. 96-102. 29/05/02. São Paulo: Editora Abril.

WEBER, Max (1980). Economía y sociedad, esbozo de sociología compreensiva. Traducido por José Medina Echavarría, Juan Roura Parella, Eugenio Ímaz, Eduardo García Máynez y José Ferrater Mora. México: Fondo de Cultura Económica. 